\title{
ALUNOS DISLÉXICOS E O APOIO PSICOPEDAGÓGICO NA APRENDIZAGEM DA LÍNGUA INGLESA
}

\author{
Emilly Cecilia Santos de Souza \\ Railson Brito de Souza \\ Randerson José da Silva \\ Vitória de Lima Crasto \\ Diogenes José Gusmão Coutinho
}

RESUMO: Compreensão da dislexia e principais estratégias psicopedagógicos para ajuda aprender Língua Inglesa o aluno portador da dislexia de uma forma inclusiva, como os docentes da área podem trabalhar de modo eficiente as necessidades especiais no aprendizado do aluno disléxico de uma Língua Estrangeira (inglês) dentro do ambiente escolar. O desenvolvimento da aprendizagem e aquisição da L2 de um aluno disléxico. Tendo, as etapas do processamento da linguagem e a maturação da aprendizagem na modalidade escrita e oral. Para tanto, a pesquisa foi norteada por estudiosos tais como: Margaret Snowling, Joy Stackhouse; Gisselli Massi entre outros, cujos trabalhos contribuem com meios que ampliem a área estudada, no sentido de implementar estratégias efetivas e precoce de intervenção no ensino/aprendizagem de uma Língua Estrangeira, a Língua Inglesa para alunos disléxicos. Abordamos o ensino da Língua Inglesa numa forma inclusiva, e como os docentes da área com auxílio dos psicopedagogos, podem trabalhar de modo eficiente com alunos que têm necessidades especiais no processo ensino/aprendizagem, como alunos disléxicos.

Palavras-chave: Processo de ensino/aprendizagem. Estratégia de Ensino de Língua Inglesa. Aluno disléxico. Psicopedagogo.

ABSTRACT: Understanding of dyslexia and major psychopedagogical strategies to help learn English language students with dyslexia in an inclusive way, as teachers in the area can efficiently work the special needs in the learning of dyslexic students of a foreign language (English) within the environment school. The development of learning and acquisition of the $\mathrm{L}_{2}$ of a dyslexic student. Having, the stages of the processing of the language and the maturation of the learning in the written and oral modality. To do so, the research was guided by scholars such as: Margaret Snowling, Joy Stackhouse; Gisselli Massi and others, whose work contributes with means to expand the area studied, in order to implement effective and early intervention strategies in the teaching / learning of a Foreign Language, the English Language for dyslexic students. We approach English language teaching in an inclusive way, and as teachers in the area with the help of psychopedagogues, can work efficiently with students who have special needs in the teaching / learning process, such as dyslexic students. 
Keywords: Teaching / learning process. English Language Teaching Strategy. Dyslexic student. Psychopedagogue.

\section{INTRODUÇÃO}

Tal caracterização veicula a dificuldade da criança à codificação e decodificação de palavras simples e descontextualizadas. Visão esta que concebe a língua como um código organizado em função de um conjunto de sons, letras, sílabas e palavras isoladas de um contexto significativo e, o aprendiz como um ser passivo e mero memorizador de repetições. (MASSI, 2007, p.II9).

Nesse contexto, profissionais da área de ensino de línguas se deparam com algumas limitações, dentre as quais, alunos com dificuldades de aprendizagem. Uma dificuldade apontada em algumas pesquisas (MASSI, 2007), como um quadro de dislexia, um distúrbio de linguagem diretamente relacionado a palavras e letras que provoca uma dificuldade específica na aprendizagem da identificação dos símbolos gráficos, mais observável na leitura e escrita, acarretando alto grau de dificuldade na ortografia. O primeiro momento da aprendizagem de uma Língua estrangeira, e a funcionalidade comunicativa. A habilidade de usar outros sons, que não os da língua mãe, para a comunicação, estabelecimento de relação entre situação língua. Levase em consideração os sons ganhando formas escritas letras e consequentemente, palavras e texto sendo necessárias outras habilidades, tais como a leitura e a escrita.

Assim, tendo-se em vista a dificuldade de se trabalhar com alunos disléxicos, uma das dificuldades é encontrar material adequado que responda à essa demanda, ajudar os professores com ferramentas simples técnicas facilitadoras para o desempenho do ensino para compreender, explorar e descrever acontecimentos relacionados com os alunos disléxicos aprendem sua Língua Materna e a Língua Estrangeira (Inglês), nos quais estão a simultaneamente envolvidos diversos fatores (predisposição para aprendizagem, metodologias de ensino dos professores da LM e da LE).

Dentro desse contexto, existe uma dificuldade de aprendizagem específica que é neurológica de origem e que é caracterizada por dificuldades com reconhecimento preciso das palavras e por pobres ortografia e decodificação. Essas dificuldades 
resultam tipicamente de um déficit e no componente fonológico da língua que é muitas vezes inesperada em relação a outras habilidades cognitivas e de prestação de instrução de sala de aula eficazes. Consequências secundárias podem incluir problemas na compreensão de leitura e reduzida experiência de leitura que podem impedir o crescimento de vocabulário e conhecimento de fundo. A dislexia é uma deficiência de aprendizagem baseado na linguagem e refere-se a um conjunto de sintomas que resultam em as pessoas terem dificuldades com competências linguísticas específicas, especialmente leitura. Uma das justificativas para o fortalecimento desse tema repousa nos fatos que fazem dessa língua (inglesa), um instrumento fundamental para participação social em nível global. Compreender a necessidade de técnicas e ações facilitadoras do processo de aprendizagem de uma Língua Estrangeira (inglês) por um disléxico.

Alguns meios estratégicos ocasionados pelos psicopedagogos poderão facilitar na aprendizagem de Língua Inglesa, assim poderão influenciar e contribuir para o aperfeiçoamento de aprendizagem, para sujeito que tem dislexia, uma vez que, o processo de aprendizado de uma Língua estrangeira inclui a memorização de sons distintos da língua materna para a comunicação. Ao apresentar uma Língua Estrangeira para um disléxico o processo poderá ser um pouco mais demorado, por haver a necessidade de repetição e técnicas diferenciadas ao favorecimento do lado cognitivo, fazendo este aluno mais participativo nas aulas de Língua Inglesa. Uma das justificativas para o fortalecimento desse tema repousa nos fatos que fazem dessa língua um instrumento fundamental para participação social em nível global.

\section{FUNDAMENTAÇÃO TEÓRICA}

\section{I IDENTIFICAÇÃO E CARACTERIZAÇÃO DO ALUNO DISLÉXICO}

De acordo com a Organização Mundial da Saúde, o que caracteriza a dislexia é: [...] um comprometimento específico e significativo no desenvolvimento das habilidades da leitura, o qual não é unicamente justificado por idade mental, problemas de acuidade visual ou escolaridade inadequada. A habilidade de compreensão da leitura, o reconhecimento de palavras na leitura, a habilidade de leitura oral e o desempenho de tarefas que requerem leitura podem estar todos 
afetados. Dificuldades para soletrar estão frequentemente associadas a transtorno específico de leitura e muitas vezes permanecem na adolescência, mesmo depois de que algum processo na leitura tenha sido feito [...] específico da leitura seguidamente tem uma história de transtornos específicos do desenvolvimento da fala e da linguagem, e uma avaliação abrangendo funcionamento corrente da linguagem muitas vezes revela dificuldades de hoje sutis. Em adição á falha acadêmica, comparecimento escolar deficiente e problemas com ajustamento social são complicações assíduas, particularmente nos últimos anos do primário e do secundário. A condição é encontrada em todas as linguagens conhecidas, mas há incerteza se a sua frequência é afetada ou não pela natureza da linguagem e do manuscrito (Organização Mundial, 1993, p.240).

Apesar das diferentes definições de dislexia e opiniões de especialistas, estes, em grande parte, concordam em dois pontos básicos. Em primeiro lugar, a dislexia é identificável como uma dificuldade de desenvolvimento da aprendizagem de línguas e cognição. Em segundo lugar, o debate de longa duração sobre a sua existência deve dar caminho para a construção experiência profissional na identificação de dislexia e desenvolver formas eficazes de ajudar os alunos a superar seus efeitos. De acordo com Margaret Snowling (2004) as características dos disléxicos são as dificuldades na consciência fonológica, memória verbal e velocidade de processamento. Alunos com dislexia geralmente têm dificuldades com outras competências linguísticas, tais como ortografia, escrita e pronuncia das palavras. A dislexia ocorre em toda a gama de capacidades intelectuais. Então, o perfil do ser disléxico, e suas dificuldades, são apresentados nas seguintes situações do processo de aprendizagem: os alunos disléxicos podem também ser bem sucedido com uma determinada tarefa em um dia, enquanto experimentando dificuldade com a mesma tarefa em outro dia. Tal desempenho imprevisível cria grande ansiedade em situações novas, bem como ao interagir com colegas e adultos.

Por isso, as crianças disléxicas que tem dificuldades no domínio fonológico estão desde o início em desvantagem. As crianças disléxicas, frequentemente, continuam a confiar em um vocabulário de reconhecimento visual na leitura e, assim, cometem muitos erros de leitura visual. Elas são incapazes de abstrair as 
correspondências entre a letra e som da sua experiencia com palavras impressas e, por isso não conseguem desenvolver estratégias de leitura fonológica (fonação) (SNOWLING, 2004, p.17).

A dislexia é melhor descrita como uma combinação de habilidades e dificuldades que afetam o processo de aprendizagem em um ou mais aspectos da leitura, ortografia e escrita. Deficiências de acompanhamento podem ser identificados nas áreas de velocidade de processamento, memória de curto prazo, o sequenciamento, auditiva e/ou percepção visual, linguagem falada e habilidades motoras. Embora muitos alunos com dislexia têm demonstrado que têm déficit de percepção visual, deficiências no tempo de processamento sensorial, ou habilidades de atenção/memória fraca, a maioria dos especialistas concorda que a dislexia é principalmente um problema com o processamento do fonema básico. Alunos disléxicos têm vários problemas com a leitura, ortografia e escrita. Eles podem ter dificuldade em adquirir consciência fonêmica, que está conectada aos sons e símbolos da linguagem. Eles podem perceber a forma de cartas de modo diferente ou ser incapaz de lembrar os nomes ou sons das letras. Muitas vezes os alunos têm problemas de escrita de algumas letras e palavras. $O$ seu trabalho escrito aparece confuso e incluem ortografia irregular e erros. Esses erros são devido ao estudante não ser capaz de identificar os sons nos movimentos corretos, a fim de escrever uma palavra.

Quanto às características de leitura primária/ortografia da dislexia, dificuldade em ler palavras em isolamento, dificuldade em descodificar com precisão palavras, isso acontece de forma sem sentido e lenta imprecisa, falta de leitura fluente. A dificuldade em aprender a soletrar são sinais de dislexia na leitura e escrita. O desenvolvimento da consciência fonológica, incluindo segmentação, de mistura, e manipular sons em palavras, a aprendizagem dos nomes das letras e seus sons associados a memória, como também a nomeação rápida de objetos familiares e cores. De acordo com Giselle Massi (2004) existem outros tipos de dificuldades, tais como, dificuldade variável com aspectos de compreensão de leitura, e dificuldade variável com aspectos da composição escrita. Uma quantidade limitada de tempo gasto em atividades de leitura, evidencia a dislexia. Essa atividade deficitária pode 
ser associada com dislexia, se eles são inesperados para a idade do indivíduo, nível educacional ou habilidades cognitivas.

\subsection{ENSINO INCLUSIVO DE INGLÊS COMO LÍNGUA ESTRANGEIRA}

Mauro Muskat e Sueli Rizzutti (2012) apontam que sobre o ensino inclusivo, deve-se ter um reflexo avaliativo do progresso do aluno durante a instrução nas aulas. $\mathrm{O}$ docente precisa colocar informações adicionais, e também, inclui os resultados de algumas ou de todas as características referente ao aluno que apresenta alguma dificuldade de aprendizagem e na linguagem: Exames de visão; A triagem auditiva; Relatórios de sala de aula do professor com suas observações; Avaliação da série; A leitura basal; Acomodações fornecidas por professores de sala de aula; E finalmente relatórios de progresso evolutivo escolar do alunado. $\mathrm{O}$ ensino inclusivo, é direcionado para as necessidades usuais de uma criança excepcional. Apresenta uma proposta ampla de todas as crianças, com necessidades especiais ou não, estarem numa escola comum. $O$ aluno considerado especial deve ser trabalhado individualmente, mas de modo articulado a todo o grupo da sala de aula. A inclusão de crianças com necessidades educacionais especiais no ensino regular pode proporcionar muitos benefícios. Entre eles, efeitos terapêuticos decorrentes diretamente da interação do aluno especial com as outras crianças. A escola que tem ensino inclusivo deve usar materiais especiais, ensino de técnicas ou equipamentos e / ou instalações, além de profissionais especializados. E nas aulas de Língua Estrangeira, é um fator importante de uma atenção maior do acompanhamento inclusivo, pois estará trabalhando com um idioma (Língua Inglesa), que há um distanciamento e diferenciação com a Língua Materna, doravante, a Língua Portuguesa. Retornando ao ensino inclusivo, é importante ter este processo de acompanhamento do docente com o discente, as avaliações, e seguida de uma reunião com os pais ou responsável, implantar nas aulas de línguas, um teste de proficiência em Inglês limitado (todos os anos disponíveis), com perspectiva de análise da sua fala e linguagem. Importantíssimo, ter uma triagem através de um processo de encaminhamento (Inglês e língua nativa, se 
possível). Mauro Muskat e Sueli Rizzutti (2012) consideram que o conhecimento e as habilidades necessárias para ensinar a ler incluem o seguinte: A psicologia da leitura e leitura de desenvolvimento, noções básicas sobre a leitura, e as características dos leitores; Fatores ambientais e fisiológicas em desenvolvimento da sua leitura, como a leitura e sua ortografia; Desenvolver o conhecimento da estrutura de linguagem, incluindo a fonologia, fonética, morfologia, ortografia, semântica, sintaxe e texto estrutura. As habilidades e práticas de instrução são primordiais para o ensino inclusivo - $\mathrm{O}$ uso de práticas de ensino validadas, e com avaliação da leitura e escrita eficientes em sala de aula. $\mathrm{Na}$ visão de Anita Givens (2010) acredita que a intervenção de alta qualidade na habilidade de linguagem, na parte oral, deve ser fortes.

A capacidade de manter a atenção, também. Um bom apoio familiar / cuidador. Os problemas que podem causar nos alunos do ensino inclusivo, é a falta desta intervenção, resultando-se em dificuldades de aprendizagem que ocorrem pelo reconhecimento tardio e intervenção, resumindo-se ao um ensino deficiente. Então, a autora Denise Santos (2012) destaca ao ensino de línguas que: Cabe ao professor avaliar as condições contextuais de seu trabalho com o ensino de Língua Inglesa e tomar decisões fundamentais sobre as estratégias mais relevantes em seu contexto, sobre quando e como apresentá-las e sobre como oferecer oportunidade de sistematização dessas estratégias. O envolvimento dos alunos nessas tomadas de decisão é sempre recomendável uma vez que o sucesso dessa aprendizagem depende da conscientazação e comprometimento dos aprendizes nesse processo. (SANTOS, 2012, p.35).

O uso de testes padronizados de leitura e escrita são importantes para avaliar o progresso do alunado no campo do ensino inclusivo, juntamente com evidência de progresso do ensino inclusivo da Língua Inglesa.

\subsection{A AÇÃO DO PSICOPEDAGOGO}

Pelo simples fato de o desenvolvimento da fala e da linguagem de uma criança ser atípico, não significa que ele não vá mudar. As mudanças ocorrem com a 
maturação, com a intervenção e porque exigências diferentes são feitas á criança á medida que ela vai ficando mais velha. (STACKHOUSE, 2004,p.28).

Anita Givens (2010) também reforça a parte dos resultados de testes padronizados, e disponíveis, como suporte. Amostras de trabalho indicando problemas de processamento de linguagem do aluno disléxico. Várias intervenções, são atualmente utilizadas no programa de ensino inclusivo e regular. Qualquer informação adicional por parte dos pais e de outros componentes são fontes de avaliação para a dislexia. A Valerie Muter (2004) acredita na prioridade da identificação das dificuldades, para estabelecer uma intervenção ligada a um sistema estratégico de aprimoramento no processo de aprendizagem, de acordo com. Isso ela, comenta, que: A importância da identificação precoce da deficência de leitura, incluindo a dislexia, tem atraído uma atenção crescente de professores, psicólogos, fonoaudiólogos, e até da mídia nos últimos io anos. $O$ ímpeto de desenvolver os instrumentos de avaliação e intervenção constituiu um passo importante na identificação precoce e no manejo sistemáticos de crianças em risco de apresentar problemas de leitura. (MUTER, 2004,p.43).

Um programa estratégico eficaz para os alunos com dislexia nas aulas de Língua Inglesa, devem incluir os seguintes processos: Individualizado - refere-se à personalização de instrução da habilidade dos alunos e seus níveis, interesses e estilos de aprendizagem. Multissensorial - refere-se à utilização combinada de visual, auditiva, cinestésica, e tátil para reforçar o aprendizado. Qual o significado de ensino multissensorial? Ensino multissensorial é um aspecto importante da instrução para os alunos disléxicos que é usado por professores clinicamente treinados. Aprendizagem multisensorial é necessária porque envolve a utilização simultânea dos três principais modos de aprendizagem: visual, auditivo, e cinestésico (movimento muscular). Os alunos que têm problemas de memória visuais podem fazer e manter conexões entre a forma oral e escrita do idioma, somente se os modos de aprendizagem auditivas e cinestésicas são utilizados na linguagem, através do treinamento e sendo bem avaliado. 
Mohammad Ali Salmani Nodoushan (2009) considera primordialmente, ter uma instrução intensiva na fonética, que é essencial para alunos disléxicos. Os alunos não podem aprender a soletrar memorizando listas de palavras semanais e não podem aprender a ler pela palavra-vista método se eles têm uma memória visual ineficaz. No entanto, eles podem e devem aprender a unidades fonéticas que representam sons da fala. Portanto, uma estrutura, fonética sistemática programada deve ser ensinado em uma progressão lógica e cumulativa. De acordo com o autor, como seria esta instrução: Intensivo dada todos os dias ou muito frequentemente durante temposuficiente. Habilidades componentes explícitas para leitura, ortografia e escrita são explicados, diretamente ensinado e modelado por o professor. Crianças são desencorajados de adivinhar em palavras. Sistemática e cumulativa tem uma sequência definida, lógica de apresentação conceito; conceitos são ordenados das mais simples às mais complexas; cada novo conceito baseia-se em conceitos previamente introduzidos, com construído em avaliar para ajudar à memória e recuperação. Estruturada tem procedimentos passo-a-passo para a introdução, revisar e praticar conceitos. Ligações multissensoriais, como: ouvir, falar, ler e escrever juntos; envolve o movimento de aprendizagem. Anita Givens (2010) fala uma abordagem diferente para a aprendizagem de línguas daquela empregada na maioria das salas de aula.

Eles precisam ser ensinados, lento e cuidadosamente, os elementos básicos de sua linguagem "os sons e as letras que os representam" e como colocá-los juntos e desmontá-los. Eles têm que ter muita prática em ter sua escrita mãos, olhos, ouvidos e vozes a trabalhar em conjunto para a organização consciente e retenção de seu aprendizado. Consequentemente aprende através de tais situações da vida realista as crianças disléxicas armazenados geralmente repertório verbal no longo - termo memória. $\mathrm{Na}$ parte acústica, o método fonético é provavelmente o método mais conhecido e amplamente utilizado de ensino, leitura e escrita na língua-alvo (em Inglês). Ensino fundamental que combina junto os sons das letras do alfabeto e suas grafias. O objetivo da instrução fônica é ensinar os alunos disléxicas no mais com um método para diferenciar os sons das letras e sua ortografia. Os alunos com dificuldades específicas de aprendizagem (dislexia) podem encontrar o estágio 
alfabético e disléxicos também, enquanto aprendem Inglês como segunda língua tendo dificuldades em correspondência com símbolo - som. 


\section{RESULTADOS E DISCUSSÕES}

As experiências de linguagem enriquecidos: ouvir, falar, e contar histórias. Evidências crescentes sugerem que a maioria dos alunos com problemas de leitura pode fazer ganhos significativos na leitura se fornecidas sistemática, explícita e leitura intensiva instrução com base em elementos críticos associados ao melhor lendo como consciência fonêmica, fonética, fluência no reconhecimento de palavras e leitura do texto, e compreensão. O progresso do estudante determina o comprimento de intervenção. Formulado uma lista abaixo baseado na leitura do material, Anita Givens (2010), e Mohammad Ali Salmani Nodoushan (2009) que assinalam uma série de coisas encontrado para ajudar nas dificuldades mais amplas às vezes vividas por alunos disléxicos na sala de aula, no seguinte aspecto de aprendizagem de línguas: Instruções - uma instrução de cada vez: Se o aluno tem um monte de informações ou instruções para dar, tem de quebrá-lo em mais curtos 'pedaços' da linguagem, parando depois de cada um. O bloco longo da linguagem falada pode ser difícil de processar em uma só vez. o que significa - para tentar. O professor, deve certificar-se de usar algo mais ou explicar com cuidado. Re-ordenação: $O$ professor deve dizer coisas na ordem que você quer que eles para ser feito. Assim, em vez de 'Antes de escrever sua lição de casa para baixo, limpar a equipamentos ', dizem,' limpar o equipamento. Então anote sua lição de casa.

Reduzir a quantidade que você diz: Estudos têm mostrado que, em algumas salas de aula, o estudante pode falar por até a 90\% do tempo. Para um jovem com dislexia, isso pode sentir esmagadora. Pense sobre a estruturação e lições atividades para que haja uma mistura de tipo de atividade empregada na sala de aula.

Desacelere: Mesmo abrandar o seu falar (o docente) um pouco significa que os alunos dar respostas mais longas, e o professor cogita a falar mais. Isso não significa que o professor tem que começar a falar com uma voz cantante. E sim, dar o apoio visual: usar mapas, gesto, pensamento / conceito, demonstrando, esboços rápidos.

Apoio Visual pode assumir muitas formas diferentes: Jovens com dislexia encontrar informações mais fáceis de entender e processo, se for completada por 
alguma coisa com um forte impacto visual. Este poderia ser um gesto natural; expressão facial; utilizar de imagens; vídeo; desenhos rápidos no quadro branco; uso a lousa interativa; conexão à Internet; usando reais objetos; demonstrar ou mostrando em vez de dizer; usando a mente mapas no quadro.

Evite expressões idiomáticas, sarcasmo, duplos sentidos: Todas as frases de uso, esteja ciente (docente) de vezes quando usa uma linguagem que é inferencial ou pode ter um duplo significado - para tentar certifique-se de usar algo mais ou explicar com cuidado.

Simplifique a gramática: Muitas vezes, o professor usa frase complexa quando um mais simples faria tão bem. Algumas frases são muito difíceis para os jovens com dislexia para entender como voz passiva, por exemplo 'Mostre-me quem era o menino que foi empurrado', ou Frases incorporadas, por exemplo, "Coloque o que você pensou que era ao lado da taça que fervida ' em Língua Inglesa. Tente (docente) simplificar as suas frases.

Pausa depois de ter feito uma pergunta: Sabemos que os professores muitas vezes fazem uma pausa muito brevemente quando têm fez uma pergunta antes de mudar de um aluno para outro, ou saltar com outra pergunta. Os jovens com dislexia muitas vezes precisam de mais "tempo de processamento" para obter os seus pensamentos em conjunto e formular uma resposta. Esperar mais tempo por uma resposta pode ajudar muito esses alunos a se envolver e contribuir. Às vezes, isto não é possível, mas não são frequentemente momentos em que você pode esperar - ele não tem que ser um espaço vazio, ser ciente das estratégias de tornando-se sentir mais natural, para exemplo, fazer uma pergunta e dizer que você está voltando para o responder, ou ligar e escrever algo sobre a bordo.

Comentando sobre o assunto exposto na aula: Para os alunos com dislexia, comentando sobre o que são fazendo, e fazendo uma pausa, ao invés de fazer perguntas, incentiva diálogo e apoia o seu pensamento e aprendizagem. Tomando nota. Há uma série de maneiras de estruturar anotações - a palavra chave sendo "estrutura". A primeira regra é estar preparado. Os alunos precisam: certificar-se de que tenham concluído qualquer leitura de fundo ou preparação antes da aula e 
fizeram uma nota de qualquer questões importantes que têm de estar cientes de; usar um linear ou estampados formato de anotar os pontos principais como palavraschave e frases; usar abreviaturas sempre que possível; deixar de fora as pequenas palavras como 'o', 'é', 'a', mas certifique lembre-se que eles 'não' e 'não' são palavras importantes; números, recordes, nomes, datas e títulos; definições de gravação com cuidado; gravar forma clara e concisa as conclusões do professor; marcar quaisquer pontos não compreendidos; diagramas de cópia com cuidado; tem um amigo ou colega que irão partilhar as suas notas ou usar um pedaço de papel.

De acordo com Maggie Vance (2004) os pais dos alunos / cuidadores terão de estar envolvidos na fase de monitoramento e na avaliação. Eles se tornam parte da equipe formada pelo professor da turma e professores especializados disponível para realizar mais perto observações. Avaliação e estabelecer um ponto de partida claro para uma abordagem de ensino que é sistemática e repetitiva (particularmente em relação a fonética) e tem igualmente em conta a compreensão da linguagem processa na alfabetização aprendendo. E a avaliação de competências examina a criança de abordagens à aprendizagem, por exemplo, como fluente, é de recordar letras e palavras, quantas repetições parecem ser necessárias antes de novo aprendizagem é mantida. Deficiências na fonológica, processamento e memória podem serem avaliados ou inferida a partir destas observações e exames complementares destas habilidades.

\section{METOdologia}

A metodologia é de modo exploratório e foi selecionado informações através de levantamentos de dados teóricos, como livros e artigos científicos encontrados em websites acadêmicos, durante dois meses. A pesquisa desenvolveu-se metodologicamente, com um levantamento bibliográfico a partir de um levantamento de literatura em fontes de informações primárias e secundárias, a exemplo de bases de dados, livros, artigos etc. A sua divisão possuir: 3 seções. $O$ trabalho é constituído de seções especificamente enquadrados de indicadores direcionados a pesquisa.

\section{CONSIDERAÇÕES FINAIS}


Este distúrbio, é referido como uma dificuldade de aprendizagem, porque a dislexia pode tornar muito difícil para um aluno a ter sucesso escolar no ambiente típico de instrução, e em suas formas mais graves, vai qualificar o aluno para a educação especial, acomodações especiais, ou serviços de apoio extra. As causas exatas da dislexia ainda não são completamente claras, mas estudos anatômicos e de imagens do cérebro mostram diferenças na forma como o cérebro de uma pessoa disléxica desenvolve e funções. Além disso, a maioria das pessoas com dislexia têm sido encontrados a ter problemas com a identificação do discurso separado sons dentro de uma palavra e / ou aprender letras representam os sons, um fator-chave em suas dificuldades de leitura. A dislexia não é devido a qualquer falta de inteligência ou vontade de aprender; com métodos de ensino apropriados, os disléxicos podem aprender com êxito. Para melhorar o ensino, a aprendizagem e os resultados para crianças com alfabetização e dislexia dificuldades: Reforçar o ensino e a aprendizagem nas aulas de Língua Inglesa, podemos usar das estratégias e programar uma forma de assistência que possa guiar a este aluno disléxico no seu processo de aprendizagem.

\section{REFERÊNCIAS}

ASSOCIAÇÃO.BRASILEIRA.DE.DISLEXIA.(ABD).Disponível.em:<www.dislex i a.org.br>. Acesso em: 24 de Abril de 2015. BRAGA, Junia (Org.). Integrando tecnologias no ensino do Inglês nos anos finais do Ensino Fundamental. São

Paulo: SM, 2012. BRUNO, Fátima.Cabral..Ensino-Aprendizagem de Línguas Estrangeiras: Reflexão e Prática..São.Paulo:.Clara.Luz..2005.

GIVENS, Anita (Org.). The Dyslexia Handbook: Procedures Concerning Dyslexia and Related Disorders. The Texas Education Agency.Austin, Texas, 2010. Disponível em: <copyrights@tea.state.tx.us.> Acesso em: I8 Maio de 202I. HAMMOND, Jill;

HERCULES, Fabian. Understanding Dyslexia: An Introduction for Dyslexic Students in Higher Education.Scottish Higher Education Funding Council. Disponível em: < www.gsa.ac.uk>. Acesso em: 18 Maio de 2021 
INTERNATIONAL.DYSLEXIA.ASSOCIATION..Disponível.em.:<www.interdy s.or g/about_od.stm > . Acesso em : 13 de Julho de 202I

JAKOBSON, Roman. Dois aspectos da linguagem e dois tipos de afasia. São Paulo: Cultrix, 2003.

KLEIN, Hanna. Avaliação das dificuldades de linguagem em crianças e em adolescentes. In: SNOWLING, Margaret; STACKHOUSE, Joy. Dislexia, fala e linguagem: Um manual do profissional. Tradução de Magda França Lopes. Porto Alegre: Artmed, 2004 .

MASSI, Giselle. A dislexia em questão. 2. ed.São Paulo: Plexus Editora, 2007.

MUSZKAT, Mauro; RIZZUTTI, Sueli. Paulo:Cortez, 2012.Vol.8. O Professor e a dislexia.

MUTER, Valerie. Antevendo as dificuldades de leitura e de ortografia das crianças. In: SNOWLING, Margaret; STACKHOUSE, Joy. Dislexia, fala e linguagem: Um manual do profissional. Tradução de Magda França Lopes. Porto Alegre: Artmed, 2004. p.43-56

MISSISSIPI DYSLEXIA HANDBOOK: Guidelines and Procedures Concerning Dyslexia and Related Disorders. Mississippi Department of Education. Jackson, MS, rev 2002. Disponível em: < http://acad/id/curriculum/laer/index.html.> Acesso em: I8 Maio de 2015.

NODOUSHAN, Mohammad Ali Salmani (Org.). Elements of English Language: Teaching for Dyslexics. The modern journal of applied linguistics.Annamalai University, vol. I, n. 2, 2009.Disponível em: <lingdaya@rediffmail.com>Acesso em: i8 Maio de 2015. SANTOS, Denise. Ensino de Língua Inglesa em foco em estratégias. São Paulo:Disal,2012.

SNOWLING, Margaret; STACKHOUSE, Joy. Dislexia, fala e linguagem: Um manual do profissional. Tradução de Magda França Lopes. Porto Alegre: Artmed, 2004. ORGANIZAÇÃO MUNDIAL DA SAÚdE (Coord.) The ICD-ro Classification of mental and behavioural disordes Clinical descriptions and 
diagnostic guidelines. Tradução de Dorgival Caetano. Classificação de transtornos mentais e de comportamento da CID ıo: descrições clínicas e diretrizes diagnósticas. Porto Alegre: Artes Médicas, 1993. Disponível em <www.cidıo.hpg.com.br>Acesso em ro de Maio de 2015.

VANCE, Maggie. Avaliação da habilidade de processamento da fala nas crianças: Uma análise de tarefas. In: SNOWLING, Margaret; STACKHOUSE, Joy. Dislexia, fala e linguagem: Um manual do profissional. Tradução de Magda França Lopes. Porto Alegre: Artmed, 2004. 